\title{
Facile Preparation of Hierarchically Porous Aromatic-cyclodextrin Polymers and Their Application for the Selective Adsorption of Cationic Dyes
}

\author{
Huiling Duan ( $\nabla$ duanhl@sxau.edu.cn ) \\ Shanxi Agricultural University \\ Xiang-Ai Ma \\ Shanxi Agricultural University \\ Yu Wang \\ Shanxi Agricultural University \\ Kai-Qi Cheng \\ Shanxi Agricultural University \\ Li-Juan Zhang \\ Shanxi Agricultural University \\ Ji-Chao Qi \\ Shanxi Agricultural University
}

\section{Research Article}

Keywords: Cyclodextrin, diazonium salts, water treatment, porous material, adsorption

Posted Date: August 30th, 2021

DOl: https://doi.org/10.21203/rs.3.rs-832204/v1

License: (c) This work is licensed under a Creative Commons Attribution 4.0 International License.

Read Full License 


\section{Abstract}

Porous $\beta$-cyclodextrin-containing materials have significant potential as adsorbents for the removal of pollutants from water. However, preparing these porous polymers in the aqueous phase is challenging. In this study, a kind of novel porous aromatic-cyclodextrin polymers (P-aro-CDPs) was designed and synthesized in aqueous solution under mild conditions by exploiting covalence-crosslinking reaction. Paro-CDPs were characterized using a variety of methods, which revealed that P-aro-CDPs have a hierarchical porous structure, a highly negatively charged surface, and rich in hydroxyl groups. The prepared P-aro-CDPs showed excellent removal efficiency for methylene blue, with a maximum adsorption capacity of $194.17 \mathrm{mg} \mathrm{g}^{-1}$. The adsorption data are well fitted to the pseudo-second-order kinetic model and the Langmuir isotherm. The as-synthesized P-aro-CDPs material exhibited superior adsorption selection toward cationic dyes than anionic dyes whether in single or multicomponent systems. Further, the P-aro-CDPs adsorbent are reusable, and good performance over six adsorptiondesorption cycles was demonstrated. Due to its off-the-beaten-path synthesis, low cost, excellent removal efficiency, and recyclability, P-aro-CDPs have great potential for use as an adsorbent in water-treatment applications.

\section{Introduction}

Globally, increasing industrialization has resulted in increased environmental pollution, and this poses a serious risk to human health [1]. In particular, water pollution exacerbates water shortages, places constraints on economic development, and limits social progress [2; 3]. Therefore, it is crucial to remove the pollutants from contaminated water for alleviating pressure on the planet's limited water resources [4]. Water pollutants include dyes, other organic pollutants, and heavy metals [5]. When discharged as effluents, dyes pose a threat to public health, environment, and ecosystems due to their high toxicities, environmental persistence, and potential for bioaccumulation [6]. Existing wastewater treatment methods include adsorption [7, 8], membrane separation [9, 10], chemical oxidation [11], photocatalysis $[12 ; 13]$, and Fenton degradation $[14,15]$. Among these methods, adsorption is regarded to be the most effective and reliable method due to its accessibility and low cost [16-18]. Porous materials are particularly suitable sorbents for the removal of dyes on account of their high specific surface areas (that is, large numbers of active sites for the adsorption of dye molecules) and their surface functional groups and internal structures [19-23].

$\beta$-Cyclodextrin ( $\beta-C D)$ is a naturally occurring compound; it is also inexpensive, nontoxic, biocompatible, and biodegradable. $\beta$-CD has a hydrophobic central cavity and a hydrophilic external surface, and can form host-guest complexes with a variety of organic compounds [24, 25]. These unique characteristics have resulted in the use of $\beta-C D$ in a number of applications, including drug delivery[26] and chiral recognition [27-29], and as structural building blocks [30-32]. In particular, $\beta$-CD has been employed as a "green" building block for the construction of a variety of materials [33-35]. $\beta$-CD-based polymers are lightweight, chemically diverse, and easily processable [17,36-38] , and have been prepared using crosslinking agents based on flexible structures, such as epichlorohydrin [39], and rigid structures, such 
as tetrafluoroterephthalonitrile [40-44]. The use of rigid crosslinking agents results in the formation of polymers with rapid adsorption rates when used as sorbents [45] because the rigid crosslinkers increase pore formation and, as a consequence, the specific surface area of the sorbent [46, 47]. Thus, CD-based polymers have attracted significant attention for use in separation processes and water-treatment applications owing to their porous structure, dispersibility, adsorption capacity, and selectivity $[30,45,48-$ 52]. However, porous CD-based polymers have previously been prepared in organic phases, and the synthesis of these polymers in the aqueous phase is challenging.

In this study, a CD polymer with a porous structure was synthesized directly in the aqueous phase using an one-pot fabrication technique. The prepared P-aro-CDPs were characterized using various spectroscopic and analytical techniques, and the adsorption performance of P-aro-CDPs for organic dyes was evaluated using methylene blue (MB) as a model dye. Finally, the adsorption performance of P-aroCDPs toward a wide range of organic dyes was also investigated.

\section{Material And Methods}

\subsection{Chemicals and materials}

Benzidine (BZD) was obtained from the Shanghai Aladdin Biochemical Technology Co., Ltd., and $\beta-C D$ was purchased from the Tianjin Kemiou Chemical Reagent Co., Ltd. All dyes (Table S1) used in our experiments were of analytical grade.

\subsection{Material synthesis}

BZD $(1.5 \mathrm{mmol})$ was placed in a $250-\mathrm{mL}$ round-bottom flask submerged in an ice bath. After iced water of $100 \mathrm{~mL}$ and iced concentrated hydrochloric acid of $0.7 \mathrm{~mL}$ were added to the flask, the solution was stirred for $15 \mathrm{~min}$ using a magnetic stirrer. Subsequently, $0.1 \mathrm{M} \mathrm{NaNO}_{2}$ of $30 \mathrm{~mL}$ was added dropwise to the solution, and the contents were stirred for a further $25 \mathrm{~min}$ to allow the full conversion of the amine to the corresponding diazonium salt. An aqueous $\mathrm{Na}_{2} \mathrm{CO}_{3}$ solution was then added dropwise until the mixture was slightly alkaline to ensure the removal of excess hydrochloric acid from the solution. $\mathrm{A}$ solution of $\beta-\mathrm{CD}(0.03 \mathrm{M})$ and $\mathrm{Na}_{2} \mathrm{CO}_{3}(0.1 \mathrm{M})$ of $30 \mathrm{~mL}$ was added to the diazonium salt solution and allowed to react for another $12 \mathrm{~h}$ with stirring. It was observed that bubbles were discharged and aggregation happened during the reaction process. The resulting mixture was centrifuged and the sediment was successively washed with water, methanol, tetrahydrofuran (THF), methanol, and water. The product was then centrifuged and the final product was vacuum freeze-dried for $12 \mathrm{~h}$ to obtain the $\mathrm{P}$ aro-CDPs product as a water-insoluble brown powder.

\subsection{Batch adsorption experiments}

For a single dye adsorption test, the P-aro-CDPs (adsorbent) of $5 \mathrm{mg}$ and the dye solution (200 $\left.\mathrm{mg} \mathrm{L}^{-1}\right)$ in $20 \mathrm{mM}$ phosphate buffer with different $\mathrm{pH}$ adjusted with $\mathrm{NaOH}$ or $\mathrm{HCl}$ of $5 \mathrm{~mL}$ were added to a $10-\mathrm{mL}$ centrifuge tube, and the tube contents were shaken at $200 \mathrm{rpm}$ in an incubator shaker at $25^{\circ} \mathrm{C}$. After 
adsorption was complete, the mixture was centrifuged, and the dye concentrations in initial solution and supernatant were monitored using UV-visible spectroscopy with an Evolution 220 spectrometer (Thermo Fisher Scientific Inc., USA) at the maximum absorption wavelength of the dyes (Table S1). The equilibrium adsorption capacity $\left(q_{\mathrm{e}}, \mathrm{mg} \mathrm{g}^{-1}\right)$ was calculated using the following formula:

$$
q_{e}=\frac{\left(C_{o}-C_{e}\right) \times V}{m}
$$

Here, $C_{o}$ and $C_{e}$ are the initial and equilibrium dye concentrations $\left(\mathrm{mg} \mathrm{L}^{-1}\right)$, respectively, $V$ is the solution volume $(\mathrm{L})$, and $m$ is the adsorbent mass $(\mathrm{g})$.

For binary dye adsorption studies, two dyes (each $200 \mathrm{mg} \mathrm{L}^{-1}$ ) were mixed together. The mixed dye solution of $5 \mathrm{~mL}$ was added to the adsorbent of $10 \mathrm{mg}$, and the mixture was shaken in an incubator shaker for different time and then centrifugated. The UV-vis spectra of the supernatant were measured.

\subsection{Adsorbent recyclability}

After MB had been adsorbed onto P-aro-CDPs, it was desorbed using ethanol. The adsorbent was washed with water and dried for $2 \mathrm{~h}$ in a freeze dryer before next use. This adsorption-desorption process was cycled for six times.

\section{Results And Discussion}

\subsection{Synthesis of P-aro-CDPs}

The P-aro-CDPs were synthesized through a covalent cross-linking process under mild conditions using water as the solvent (Fig. 1). Firstly, a diazonium salts was synthesized from BZD as the monomer by diazotization under mild reaction conditions. Subsequently, a kind of hierarchically porous arocyclodextrin polymers (P-aro-CDPs) was formed through crosslinking reaction. According to the fact of large nitrogen releasing during synthesis process and referring to literature [53], it is suggested that the polymerization reaction could be depicted as Fig. 1, and the polymers should contain main product (1) and by-product (2).

\subsection{Material characterization}

The synthesized P-aro-CDPs was subjected to FTIR, XPS, and solid-state NMR spectroscopies to investigate the chemical bonds and functional groups on its surface.

Compared the FTIR spectrum of P-aro-CDPs with that of BZD (Fig. 2A), the amine band at 3200-3400 $\mathrm{cm}^{-1}$ is absent, whereas the skeletal vibration peak of the benzene ring at $1615 \mathrm{~cm}^{-1}$ is still present. Comparison the FTIR spectrum of P-aro-CDPs with that of $\beta$-CD reveals that the $-\mathrm{OH}$ stretching band at $3420 \mathrm{~cm}^{-1}$ and the skeletal vibration peak of $\beta-C D$ at $534 \mathrm{~cm}^{-1}$ are still present. Aromatic carbon signals 
of BZD and aliphatic carbons of $\beta-C D$ are observed at $120-160 \mathrm{ppm}$ and $72 \mathrm{ppm}$ in the ${ }^{13} \mathrm{C}-\mathrm{NMR}$ spectrum of P-aro-CDPs (Fig. S1). These indicate that BZD and $\beta$-CD participated in the formation of the compound during the reaction and presented in the final structure of the synthesized polymers.

Two new peaks in FTIR spectrum of as-prepared materials corresponding to $-\mathrm{N}=\mathrm{N}$ - and $\mathrm{C}-\mathrm{O}-\mathrm{N}$ stretching bands are observed at 1400 and $1000-1200 \mathrm{~cm}^{-1}$. The results of XPS (Fig. 2B) and elemental analyses (Table S2) show that P-aro-CDPs contains $\mathrm{C}, \mathrm{H}, \mathrm{O}$, and $\mathrm{N}$, and that the two monomers had reacted on the surface. Further, the XPS spectrum of N1s (Fig. S2) could be decomposed into three single peaks that attributed to $\mathrm{C}-\mathrm{N}(399.4 \mathrm{eV}), \mathrm{N}=\mathrm{N}+(401.7 \mathrm{eV})$, and N-O (405.4 eV) functional groups [54]. These results show that by-products (2) during polymerization were existed.

The $\mathrm{N}_{2}$ adsorption-desorption isotherm of P-aro-CDPs (Fig. 2C) of type-IV reveals the presence of microand mesopores, as evident from the pore-size distribution curve. The BET surface area and the pore volume of P-aro-CDPs were calculated to be $67.6 \mathrm{~m}^{2} \mathrm{~g}^{-1}$ and $0.2767 \mathrm{~cm}^{3} \mathrm{~g}^{-1}$, respectively. From the poresize distribution curve, pores with diameters $<2 \mathrm{~nm}$ are mainly concentrated at $0.8 \mathrm{~nm}$, which indicates the presence of the $\beta$-CD monomer. Thus, P-aro-CDPs have hierarchical porous structure and high specific surface area, and may be a promising adsorbent for aqueous pollutants.

The TGA results (Fig. 2D) show that P-aro-CDPs are relatively stable at temperatures below $250{ }^{\circ} \mathrm{C}$, and that its thermal behavior can be divided into three stages. A weight loss of approximately $5 \%$ was observed in the first stage $\left(0-200^{\circ} \mathrm{C}\right)$, corresponding to the loss of water adsorbed on the outer surface layer. A second weight loss of approximately $10 \%$ was observed at $200-250{ }^{\circ} \mathrm{C}$, attributing to internal polymer dehydration. Finally, the third weight loss of $10-30 \%$ occurred at $250-600{ }^{\circ} \mathrm{C}$, ascribing to the degradation and carbonization of the polymer backbone.

Zeta potential analysis (Fig. 3A) revealed that P-aro-CDPs had an isoelectric point of approximately 4.0; hence, the surface of P-aro-CDPs is highly negatively charged when the $\mathrm{pH}$ is greater than 4.0 , which indicates that the as-synthesized material may be used to selectively adsorb cationic compounds.

The XRD pattern of P-aro-CDPs (Fig. 3B) exhibits a broad peak at $2 \theta=15-30^{\circ}$, which is a characteristic amorphous peak. Therefore, we deduce that the polymer network of P-aro-CDPs has an amorphous structure.

The SEM image of P-aro-CDPs (Fig. 3C) clearly shows that the synthesized polymer nanoparticles are irregularly shaped, with rough and uneven surfaces on the micrometer scale. The TEM image (Fig. 3D) reveals the presence of mesopores and micropores with a variety of diameters within the polymer as well.

\subsection{Dye adsorption performance}

\subsubsection{Effect of $\mathrm{pH}$}

The $\mathrm{pH}$ effect on the dye-adsorption performance of P-aro-CDPs was investigated ranging $\mathrm{pH} 2-12$, and the results are shown in Fig. $4 \mathrm{~A}$. MB adsorption was observed to increase gradually with increasing $\mathrm{pH}$ 
(2.0-12.0). Less $M B$ is adsorbed under acidic conditions due to the competition between protonated MB and $\mathrm{H}_{3} \mathrm{O}^{+}$for adsorption sites. In contrast, the increased negative charge on the adsorbent surface under alkaline conditions facilitates the adsorption of cationic MB, which is consistent with the earlier zeta potential results; that is, the surface of P-aro-CDPs is positively charged at the $\mathrm{pH}$ lower than the isoelectric point of P-aro-CDPs (4.0), and it is negatively charged at $\mathrm{pH}>4.0$. The P-aro-CDPs surface also becomes gradually more negatively charged as the $\mathrm{pH}$ is further increased, resulting in increased adsorption of MB on P-aro-CDPs.

\subsubsection{Effect of time}

The time-dependent adsorption rates of MB at various concentrations on P-aro-CDPs were analyzed (Fig. 4B). The adsorption rate was high and approximately $80 \%$ of the total amount of dye was adsorbed in the first $20 \mathrm{~min}$. However, the adsorbed amount still increased with time between 20-100 min, but at a slower rate. Finally, the adsorbed amount was almost constant at time greater than 150 min.

\subsubsection{Adsorption kinetics}

The adsorption kinetics of various concentrations of MB on P-aro-CDPs were analyzed by fitting the adsorption data to pseudo-first-order, pseudo-second-order, and Elovich kinetic models (Supporting Information) (Fig. 4C, S3, and S4 and Table S3). The experimental data fit pseudo-second-order kinetic model better than pseudo-first-order model, indicating that chemisorption is the rate-limiting step of adsorption process. Rate constant was observed to gradually decrease with increasing initial dye concentration, stating the fact that the adsorption rate is controlled by the rate of dye molecules binding to adsorption sites. As the number of adsorption sites on P-aro-CDPs is limited, higher dye concentration increases the ratio of adsorbates to adsorption sites, which leads to more competition for adsorption sites between dye molecules. Consequently, binding resistance increases and the binding rate descends, resulting in the overall adsorption rate reducing. Furthermore, the experimental data fit the Elovich kinetic model as well, indicating the rate-limiting step of chemisorption, which is likely due electron sharing between the hydrophilic groups on the adsorbent surface and the MB molecules.

To understand the diffusion process, in particular the rate-limiting step that determines MB adsorption onto P-aro-CDPs, the adsorption kinetics were further analyzed using the Weber-Morris intraparticle diffusion and Boyd models (Supporting Information). The process by which the dye is adsorbed onto P-aro-CDPs can be divided into three stages (Fig. S5 and S6). In stage 1, instantaneous or external surface adsorption occurs during the first 20 min of the adsorption process. Because the adsorption process had just started at this stage, there was an abundance of adsorption sites and $-\mathrm{OH}$ groups on the P-aro-CDPs surface, which facilitated the rapid adsorption of MB molecules onto P-aroCDPs through electrostatic interactions between $\mathrm{MB}^{+}$and $-\mathrm{OH}^{-}$. A change in the adsorption driving force, from electrostatic interactions to a concentration gradient, was observed in stage 2 , which occurred between 20 and $150 \mathrm{~min}$ after the start of adsorption. Because this stage involves intraparticle diffusion, 
it forms part of the rate-limiting step of the entire adsorption process. In stage 3, which occurred after 150 min, a constant rate of adsorption was observed as adsorption equilibrium was reached.

The Weber-Morris model shows that the intraparticle diffusion rate $\left(k_{p}\right)$ increases with increasing initial dye concentration, which shows that a high initial dye concentration results in a greater diffusion driving force, thereby enhancing the dye diffusion rate. Similarly, the boundary layer thickness $(C)$ also increases with increasing initial dye concentration. A higher $C$ value indicates a higher contribution of surface adsorption to chemisorption, which demonstrates that a high initial dye concentration can lead to an enlargement in thickness of diffusion boundary layer. Although the Weber-Morris plot of $q_{\mathrm{t}}$ (adsorption capacity at time $t$ ) versus $t^{0.5}$ (square root of time $t$ ) shows a linear relationship, the lines of best fit do not pass through origin, which is indicative of intraparticle diffusion. However, this is not sole rate-limiting factor. Likewise, in the Boyd plot of $B_{t}$ (the Boyd function) versus time $t$, the lines of best fit do not pass through origin. Therefore, membrane diffusion is rate-limiting step during diffusion process.

\subsubsection{Adsorption isotherms}

The equilibrium data were analyzed using three isotherm models (Supporting Information) to investigate the saturated adsorption behavior and capacity of P-aro-CDPs for MB. The analyzed results show that the adsorption equilibrium data fit Langmuir model better than Freundlich and Temkin models (Fig 4D, S7, and S8 and Table S4), suggesting that the adsorption of MB onto P-aro-CDPs is limited to a monolayer over uniform adsorption sites. The maximum adsorption capacity of P-aro-CDPs toward MB was 194.17 $\mathrm{mg} \mathrm{g}^{-1}$ calculated using Langmuir equation.

\subsubsection{Adsorption thermodynamics}

In order to investigate the adsorption mechanism for a single dye system, the thermodynamic parameters were determined. For the adsorption of MB onto P-aro-CDPs, enthalpy $(\Delta H)$ and entropy changes $(\Delta S)$ calculated using the van't Hoff equation (Supporting Information) were $11.17 \mathrm{KJ} \mathrm{mol}^{-1}$ and $35.44 \mathrm{~J} \mathrm{~mol}^{-1}$ $\mathrm{K}^{-1}$, respectively, which shows that the adsorption process is endothermic with an associated increase in

the degree of disorder. Therefore, temperature rising would increase the driving force for adsorption of $M B$ at active adsorption sites, thereby increasing the ability of P-aro-CDPs to capture MB molecules. The Gibbs free energy change $(\Delta G)$ went from positive to negative $(606.7,252.34,-102.02,-456.37$, and $-810.73 \mathrm{~J} \mathrm{~mol}^{-1}$ ) as the adsorption temperature raised from $298,308,318,328$, to $338 \mathrm{~K}$, indicating that temperature rising within a certain range promotes the spontaneous adsorption of MB onto P-aro-CDPs.

\subsection{Repeatability}

P-aro-CDPs are easily regenerated after washing several times with ethanol. It can be seen from Fig. 5A that the adsorption rate slightly decreases with increasing number of re-use cycles; however, the adsorption efficiency was maintained at above $80 \%$ after six adsorption-desorption cycles. Thus, Parol-CDPs are recyclable, and this material is a promising industrially applicable adsorbent. 


\subsection{Adsorption selectivity}

The adsorption selectivity of P-aro-CDPs was investigated using 15 dyes, including positively charged $M B$, rhodamine $B(R B)$, brilliant cresyl blue (BCB), astrazon orange $R(A O R)$, basic red 9 (BR9), auramine 0 (AO), and basic orange 21 (BO22), as well as negatively charged tartrazine (T23), acid red 73 (AR73), eosin (ES), alizarin red S(ARS), alizarin green (AG), methyl orange (MO), Congo red (CR), and sunset yellow FCF (SY) (seven cationic and eight anionic dyes). The results in Fig. 5B show that the adsorbed amount of dye onto P-aro-CDPs exceeded $70 \mathrm{mg} \mathrm{g}^{-1}$ for all cationic dyes but was less than $10 \mathrm{mg} \mathrm{g}^{-1}$ for any anionic dyes. Therefore, the adsorption properties of P-aro-CDPs are considerably better for cationic dyes than anionic dyes, indicating that P-aro-CDPs are more selective toward cationic dyes.

The adsorption behavior of P-aro-CDPs for binary dye solutions (MB/T23 and AO/TS) was investigated to further validate the adsorption selectivity of P-aro-CDPs toward cationic dyes (Fig. 5C and 5D). The cationic dye concentration in each mixed dye solution was lower after the addition of P-aro-CDPs, whereas the anionic dye concentration remained essentially unchanged, which confirms that P-aro-CDPs selectively adsorbs cationic dyes from dye solutions that contain mixtures of cationic and anionic dyes.

\section{Conclusion}

In this study, P-aro-CDPs, a porous aro-CD polymer, were synthesized from BZD and $\beta$-CD monomers through covalent cross-linking and self-assembly in aqueous solution. Notably, this green and facile preparation approach does not involve cumbersome steps or toxic organic solvents. Characterization data reveal that the as-synthesized material, which is a very stable amorphous polymer with a relatively high specific surface area, has an abundance of hydroxyl groups on its surface. The investigation of adsorption behavior of P-arol-CDPs toward MB showed that the adsorption process follows pseudosecond-order kinetic and Langmuir isotherm. Because the surface of P-aro-CDPs is negatively charged, the adsorbent selectively adsorbs cationic dyes through electrostatic interactions. Furthermore, the adsorbent is easily collected and regenerated. This simple, low-cost, and sustainable synthetic route can be used to develop further porous CD-based materials, with synthesized materials potentially useful for the adsorption, separation, and purification of cationic molecules.

\section{Declarations}

\section{Acknowledgements}

This work was supported by the Doctoral Research Project of Shanxi Agricultural University. (No. 2021BQ29).

\section{Conflict of interest}

The authors declare no competing financial interests. 
Author Contributions: Hui-Ling Duan: Conceptualization, Data curation, Methodology, Validation, Project administratin, Writing-Original Draft, Writing-Review and Editing, Funding acquisition. Yu Wang: Formal analysis and Visualization. Kai-Qi Cheng: Investigation. Li-Juan Zhang: Investigation. Ji-Chao Qi: Investigation. Xiang-Ai Ma: Conceptualization, Writing-Review and Editing, Supervision. All authors have read and agreed to the published version of the manuscript.

\section{References}

[1] Jiang G (2016) Preface to the special topic on environmental pollution and health risk. Nat/ Sci Rev 3: 409. http://dx.doi.org/10.1093/nsr/nww090.

[2] Ma T, Sun S, Fu G, Hall JW, Ni Y, He L, Yi J, Zhao N, Du Y, Pei T, Cheng W, Song C, Fang C, Zhou C (2020) Pollution exacerbates China's water scarcity and its regional inequality. Nat Commun 11: 650. http://dx.doi.org/10.1038/s41467-020-14532-5.

[3] Lu S, Li J, Tang Y, Guo M (2020) Research on standard calculation method for watershed water pollution compensation. Sci Total Environ: 138157. http://dx.doi.org/10.1016/j.scitotenv.2020.138157.

[4] Zhou Y, Lu J, Liu Q, Chen H, Liu Y, Zhou Y (2019) A novel hollow-sphere cyclodextrin nanoreactor for the enhanced removal of bisphenol A under visible irradiation. J Hazard Mater 384: 121267. http://dx.doi.org/10.1016/j.jhazmat.2019.121267.

[5] Shetty D, Boutros S, Eskhan A, De Lena AM, Skorjanc T, Asfari Z, Traboulsi H, Mazher J, Raya J, Banat F, Trabolsi A (2019) Thioether-crown-rich calix[4]arene porous polymer for highly efficient removal of mercury from water. ACS App/ Mater Interfaces 11: 12898-12903.

http://dx.doi.org/10.1021/acsami.9b02259.

[6] Rawat D, Sharma RS, Karmakar S, Arora LS, Mishra V (2018) Ecotoxic potential of a presumably nontoxic azo dye. Ecotox Environ Safe 148: 528-537. http://dx.doi.org/10.1016/j.ecoenv.2017.10.049.

[7] Ghosh A, Das G (2020) Green synthesis of Sn(II)-BDC MOF: Preferential and efficient adsorption of anionic dyes. Micropor Mesopor Mat 297: 110039. http://dx.doi.org/10.1016/j.micromeso.2020.110039.

[8] Wang Y, Wu Y, Cong H, Wang S, Shen Y, Yu B (2021) Preparation of pyridine polyionic liquid porous microspheres and their application in organic dye Adsorption. J Polym Environ.

http://dx.doi.org/10.1007/s10924-021-02203-5.

[9] Wang Q, Ju J, Tan Y, Hao L, Ma Y, Wu Y, Zhang H, Xia Y, Sui K (2019) Controlled synthesis of sodium alginate electrospun nanofiber membranes for multi-occasion adsorption and separation of methylene blue. Carbohydr Polym 205: 125-134. http://dx.doi.org/10.1016/j.carbpol.2018.10.023.

[10] Beluci NCL, Mateus GAP, Miyashiro CS, Homem NC, Gomes RG, Fagundes-Klen MR, Bergamasco R, Vieira AMS (2019) Hybrid treatment of coagulation/flocculation process followed by ultrafiltration in 
TIO2-modified membranes to improve the removal of reactive black 5 dye. Sci Total Environ 664: 222229. http://dx.doi.org/10.1016/j.scitotenv.2019.01.199.

[11] Hu EL, Shang SM, Tao XM, Jiang SX, Chiu KL (2016) Regeneration and reuse of highly polluting textile dyeing effluents through catalytic ozonation with carbon aerogel catalysts. J Cleaner Prod 137: 1055-1065. http://dx.doi.org/10.1016/j.jclepro.2016.07.194.

[12] Abukhadra MR, Shaban M, Abd El Samad MA (2018) Enhanced photocatalytic removal of Safranin-T dye under sunlight within minute time intervals using heulandite/polyaniline@ nickel oxide composite as a novel photocatalyst. Ecotox Environ Safe 162: 261-271.

http://dx.doi.org/10.1016/j.ecoenv.2018.06.081.

[13] Mohamed F, Abukhadra MR, Shaban M (2018) Removal of safranin dye from water using polypyrrole nanofiber/Zn-Fe layered double hydroxide nanocomposite (Ppy NF/Zn-Fe LDH) of enhanced adsorption and photocatalytic properties. Sci Total Environ 640-641: 352-363.

http://dx.doi.org/10.1016/j.scitotenv.2018.05.316.

[14] Fu F, Wang Q, Tang B (2010) Effective degradation of C.I. Acid Red 73 by advanced Fenton process. J Hazard Mater 174: 17-22. http://dx.doi.org/10.1016/j.jhazmat.2009.09.009.

[15] Hou N, Wang R, Wang F, Bai JH, Jiao TF, Bai ZH, Zhang LX, Zhou JX, Peng QM (2019) Self-assembled hydrogels constructed via host-guest polymers with highly efficient dye removal capability for wastewater treatment. Colloids Surf A Physicochem Eng Aspects 579: 123670.

http://dx.doi.org/10.1016/j.colsurfa.2019.123670.

[16] Ling Y, Klemes MJ, Xiao L, Alsbaiee A, Dichtel WR, Helbling DE (2017) Benchmarking micropollutant removal by activated carbon and porous $\beta$-cyclodextrin polymers under environmentally relevant scenarios. Environ Sci Technol 51: 7590-7598. http://dx.doi.org/10.1021/acs.est.7b00906.

[17] Alzate-Sánchez DM, Ling Y, Li C, Frank BP, Bleher R, Fairbrother DH, Helbling DE, Dichtel WR (2019) $\beta$ cyclodextrin polymers on microcrystalline cellulose as a granular media for organic micropollutant removal from water. ACS Appl Mater Interfaces 11: 8089-8096.

http://dx.doi.org/10.1021/acsami.8b22100.

[18] Hassan MM, Carr CM (2018) A critical review on recent advancements of the removal of reactive dyes from dyehouse effluent by ion-exchange adsorbents. Chemosphere 209: 201-219. http://dx.doi.org/10.1016/j.chemosphere.2018.06.043.

[19] Zhang C, Li Y, Li Y, Zhang W, Wang X, He X, Yu M (2019) Synthesis and Zn(II) modification of hierarchical porous carbon materials from petroleum pitch for effective adsorption of organic dyes. Chemosphere 216: 379-386. http://dx.doi.org/10.1016/j.chemosphere.2018.10.164. 
[20] Xie Y, Chen C, Lu X, Luo F, Wang C, Alsaedi A, Hayat T (2019) Porous NiFe-oxide nanocubes derived from prussian blue analogue as efficient adsorbents for the removal of toxic metal ions and organic dyes. J Hazard Mater379: 120786. http://dx.doi.org/10.1016/j.jhazmat.2019.120786.

[21] Parshi N, Pan D, Dhavle V, Jana B, Maity S, Ganguly J (2019) Fabrication of lightweight and reusable salicylaldehyde functionalized chitosan as adsorbent for dye removal and its mechanism. Int J Biol Macromol 141: 626-635. http://dx.doi.org/10.1016/j.ijbiomac.2019.09.025.

[22] Ou Q, Zhang Q-M, Zhu P-C, Zhang Q-P, Cheng Z, Zhang C (2019) Pentiptycene-based microporous polymer for removal of organic dyes from water. Eur Polym J 120: 109216.

http://dx.doi.org/10.1016/j.eurpolymj.2019.109216.

[23] Kundu S, Chowdhury IH, Naskar MK (2017) Synthesis of hexagonal shaped nanoporous carbon for efficient adsorption of methyl orange dye. J Mol Liq 234: 417-423.

http://dx.doi.org/10.1016/j.molliq.2017.03.090.

[24] Liu Y, Zhao Y-L, Zhang H-Y, Li X-Y, Liang P, Zhang X-Z, Xu J-J (2004) Supramolecular polypseudorotaxane with conjugated polyazomethine prepared directly from two inclusion complexes of $\beta$-cyclodextrin with tolidine and phthaldehyde. Macromolecules 37: 6362-6369.

http://dx.doi.org/10.1021/ma0356717

[25] Prochowicz D, Kornowicz A, Lewinski J (2017) Interactions of native cyclodextrins with metal ions and inorganic nanoparticles: Fertile landscape for chemistry and materials science. Chem Rev 117: 13461-13501. http://dx.doi.org/10.1021/acs.chemrev.7b00231.

[26] Wankar J, Kotla NG, Gera S, Rasala S, Pandit A, Rochev YA (2020) Recent advances in host-guest self-assembled cyclodextrin carriers: Implications for responsive drug delivery and biomedical engineering. Advanced Functional Materials: 1909049. http://dx.doi.org/10.1002/adfm.201909049.

[27] Chen X, Rao J, Wang J, Gooding JJ, Zou G, Zhang Q (2011) A facile enantioseparation for amino acids enantiomers using beta-cyclodextrins functionalized $\mathrm{Fe}_{3} \mathrm{O}_{4}$ nanospheres. Chem Commun (Camb) 47: 10317-10319. http://dx.doi.org/10.1039/c1cc13734d.

[28] Arslan M, Sayin S, Yilmaz M (2013) Enantioselective sorption of some chiral carboxylic acids by various cyclodextrin-grafted iron oxide magnetic nanoparticles. Tetrahedron: Asymmetry 24: 982-989. http://dx.doi.org/10.1016/j.tetasy.2013.07.015.

[29] Deng MD, Li S, Cai LZ, Guo XJ (2019) Preparation of a hydroxypropyl-beta-cyclodextrin functionalized monolithic column by one-pot sequential reaction and its application for capillary electrochromatographic enantiomer separation. J Chromatogr A 1603: 269-277. http://dx.doi.org/10.1016/j.chroma.2019.06.044. 
[30] Cheng Y, Wang Y, Wang Q, Liao Z, Zhang N, Guo Y, Xiang Z (2019) Hierarchically porous metal-free carbon with record high mass activity for oxygen reduction and Zn-air batteries. J Mater Chem A 7: 98319836. http://dx.doi.org/10.1039/c9ta02220a.

[31] Zhang Y, Duan J, Ma D, Li P, Li S, Li H, Zhou J, Ma X, Feng X, Wang B (2017) Three-dimensional anionic cyclodextrin-based covalent organic frameworks. Angew Chem Int Ed 56: 16313-16317. http://dx.doi.org/10.1002/anie.201710633.

[32] Yue L, Wang S, Zhou D, Zhang H, Li B, Wu LX (2016) Flexible single-layer ionic organic-inorganic frameworks towards precise nano-size separation. Nat Commun 7: 10742. http://dx.doi.org/10.1038/Ncomms10742.

[33] Villalobos LF, Huang T, Peinemann KV (2017) Cyclodextrin films with fast solvent transport and shape-selective permeability. Adv Mater 29: 1606641. http://dx.doi.org/10.1002/adma.201606641.

[34] Yang P, Zhao W, Shkurenko A, Belmabkhout Y, Eddaoudi M, Dong X, Alshareef HN, Khashab NM (2019) Polyoxometalate-cyclodextrin metal-organic frameworks: From tunable structure to customized storage functionality. J Am Chem Soc 141: 1847-1851. http://dx.doi.org/10.1021/jacs.8b11998.

[35] Liu J, Hua D, Zhang Y, Japip S, Chung TS (2018) Precise molecular sieving architectures with janus pathways for both polar and nonpolar molecules. Adv Mater 30: 1705933. http://dx.doi.org/10.1002/adma.201705933.

[36] Xue JH, Zhang H, Ding DX, Hu N, Wang YD, Wang YS (2019) Linear $\beta$-cyclodextrin polymer functionalized multiwalled carbon nanotubes as nanoadsorbent for highly effective removal of $\mathrm{U}(\mathrm{VI})$ from aqueous solution based on inner-sphere surface complexation. Ind Eng Chem Res 58: 4074-4083. http://dx.doi.org/10.1021/acs.iecr.8b05453.

[37] Klemes MJ, Ling Y, Ching C, Damian VW, E. Helbling, Dichtel WR (2019) Reduction of a tetrafluoroterephthalonitrile- $\beta$-cyclodextrin polymer to remove anionic micropollutants and perfluorinated alkyl substances from water. Angew Chem Int Ed 58: 12049-12053.

http://dx.doi.org/10.1002/anie.201905142.

[38] Chen H, Zhou Y, Wang J, Lu J, Zhou Y (2020) Polydopamine modified cyclodextrin polymer as efficient adsorbent for removing cationic dyes and $\mathrm{Cu}(2) . \mathrm{J}$ Hazard Mater 389: 121897. http://dx.doi.org/10.1016/j.jhazmat.2019.121897.

[39] Morin-Crini N, Winterton P, Fourmentin S, Wilson LD, Fenyvesi É, Crini G (2018) Water-insoluble $\beta$ cyclodextrin-epichlorohydrin polymers for removal of pollutants from aqueous solutions by sorption processes using batch studies: A review of inclusion mechanisms. Prog Polym Sci 78: 1-23. http://dx.doi.org/10.1016/j.progpolymsci.2017.07.004. 
[40] Li C, Klemes MJ, Dichtel WR, Helbling DE (2018) Tetrafluoroterephthalonitrile-crosslinked betacyclodextrin polymers for efficient extraction and recovery of organic micropollutants from water. $J$ Chromatogr A 1541: 52-56. http://dx.doi.org/10.1016/j.chroma.2018.02.012.

[41] Liu DS, Huang Z, Li MN, Sun P, Yu T, Zhou LC (2019) Novel porous magnetic nanospheres functionalized by beta-cyclodextrin polymer and its application in organic pollutants from aqueous solution. Environ Pollut 250: 639-649. http://dx.doi.org/10.1016/j.envpol.2019.04.079.

[42] Klemes MJ, Ling Y, Chiapasco M, Alsbaiee A, Helbling DE, Dichtel WR (2018) Phenolation of cyclodextrin polymers controls their lead and organic micropollutant adsorption. Chem Sci 9: 8883-8889. http://dx.doi.org/10.1039/c8sc03267j.

[43] Duan HL, Mou ZL, Wang J, Ma SY, Zhan HY, Zhang ZQ (2019) Magnetically modified porous $\beta$ cyclodextrin polymers for dispersive solid-phase extraction high-performance liquid chromatography analysis of sudan dyes. Food Anal Methods 12: 1429-1438. http://dx.doi.org/10.1007/s12161-01901476-w.

[44] Duan HL, Niu QL, Wang J, Ma SY, Zhang J, Zhang ZQ (2019) High uptake carboxyl-functionalized porous beta-cyclodextrin polymer for selective extraction of lysozyme from egg white. $J$ Chromatogr A 1600: 80-86. http://dx.doi.org/10.1016/j.chroma.2019.04.056.

[45] Alsbaiee A, Smith BJ, Xiao L, Ling Y, Helbling DE, Dichtel WR (2016) Rapid removal of organic micropollutants from water by a porous $\beta$-cyclodextrin polymer. Nature 529: 190-194. http://dx.doi.org/10.1038/nature16185.

[46] Ji G, Yang Z, Zhang H, Zhao Y, Yu B, Ma Z, Liu Z (2016) Hierarchically mesoporous ohydroxyazobenzene polymers: Synthesis and their applications in $\mathrm{CO}_{2}$ capture and conversion. Angew Chem Int Ed 55: 9685-9689. http://dx.doi.org/10.1002/anie.201602667.

[47] McKeown NB, Gahnem B, Msayib KJ, Budd PM, Tattershall CE, Mahmood K, Tan S, Book D, Langmi HW, Walton A (2006) Towards polymer-based hydrogen storage materials: Engineering ultramicroporous cavities within polymers of intrinsic microporosity. Angew Chem Int Ed 118: 1836-1839. http://dx.doi.org/10.1002/ange.200504241.

[48] Yu T, Xue Z, Zhao X, Chen W, Mu T (2018) Green synthesis of porous $\beta$-cyclodextrin polymers for rapid and efficient removal of organic pollutants and heavy metal ions from water. New J Chem 42 : 16154-16161. http://dx.doi.org/10.1039/c8nj03438a.

[49] Xu GZ, Xie XC, Qin L, Hu XJ, Zhang DL, Xu J, Li DW, Ji XW, Huang Y, Tu YZ, Jiang L, Wei DY (2019) Simple synthesis of a swellable porous beta-cyclodextrin-based polymer in the aqueous phase for the rapid removal of organic micro-pollutants from water. Green Chem 21: 6062-6072. http://dx.doi.org/10.1039/c9gc02422k. 
[50] Liu J, Yang Y, Bai J, Wen H, Chen F, Wang B (2018) Hyper-cross-linked porous MoS2-cyclodextrinpolymer frameworks: Durable removal of aromatic phenolic micropollutant from water. Anal Chem 90: 3621-3627. http://dx.doi.org/10.1021/acs.analchem.8b00239.

[51] Yang S, Lin ST, Fan J, Wang YR, Liu C, Yan X (2017) Rapid, complete removal of organic pollutants from water by a SnS2-modified porous $\beta$-cyclodextrin-containing polymer. Chempluschem 82: 12181223. http://dx.doi.org/10.1002/cplu.201700323.

[52] Duan H-L, Deng X, Wang J, Fan L, Yang Y-C, Zhang Z-Q (2020) Ethanolamine- and aminefunctionalized porous cyclodextrin polymers for efficient removal of anionic dyes from water. Eur Polym J 133: 109762. http://dx.doi.org/10.1016/j.eurpolymj.2020.109762.

[53] Mahouche-Chergui S, Gam-Derouich S, Mangeney C, Chehimi MM (2011) Aryl diazonium salts: a new class of coupling agents for bonding polymers, biomacromolecules and nanoparticles to surfaces. Chem Soc Rev 40: 4143-4166. http://dx.doi.org/10.1039/c0cs00179a.

[54] Salmi Z, Benzarti K, Chehimi MM (2013) Diazonium cation-exchanged clay: an efficient, unfrequented route for making clay/polymer nanocomposites. Langmuir 29: 13323-13328.

http://dx.doi.org/10.1021/la402710r.

\section{Figures}

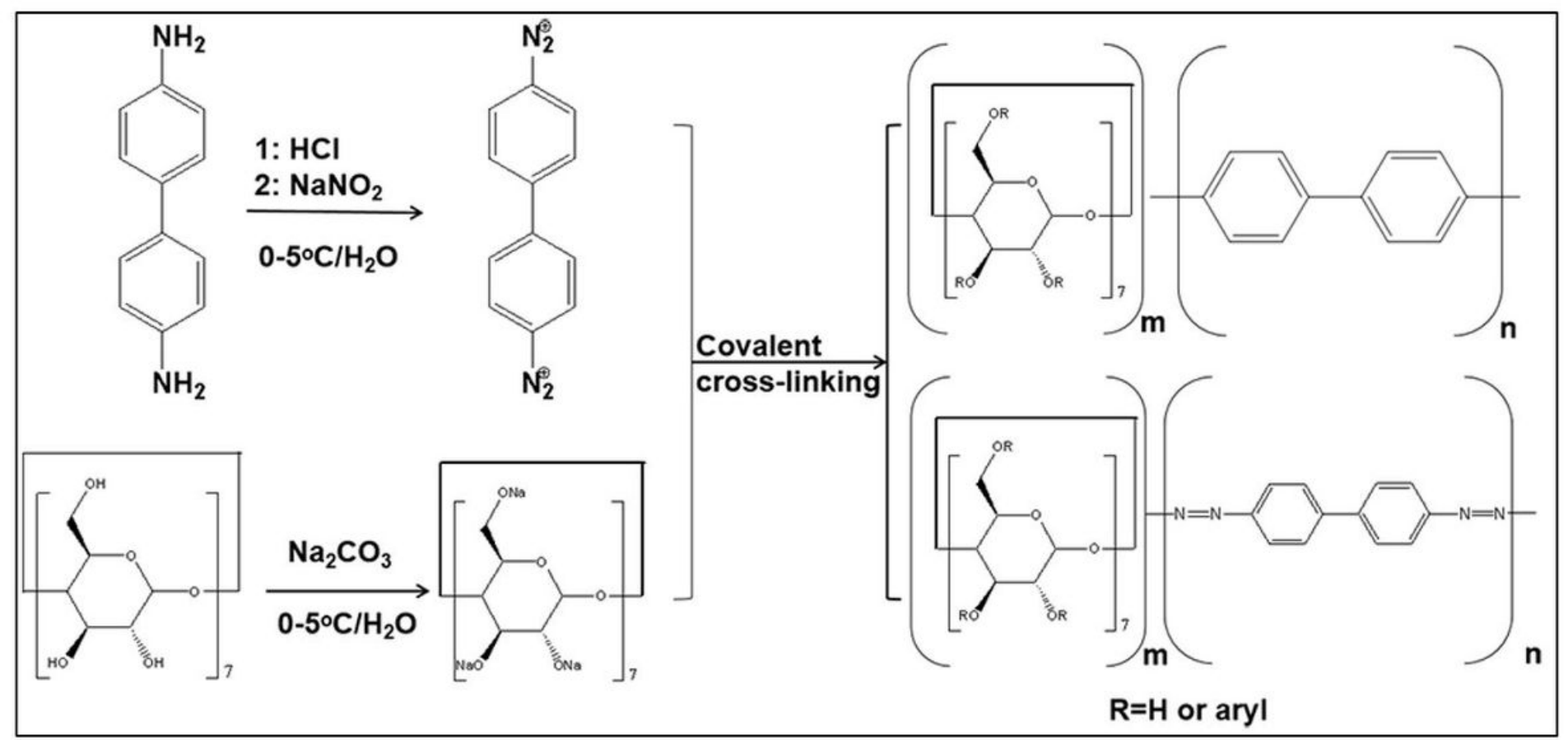

\section{Figure 1}

Schematic depicting the synthesis of P-aro-CDPs. 

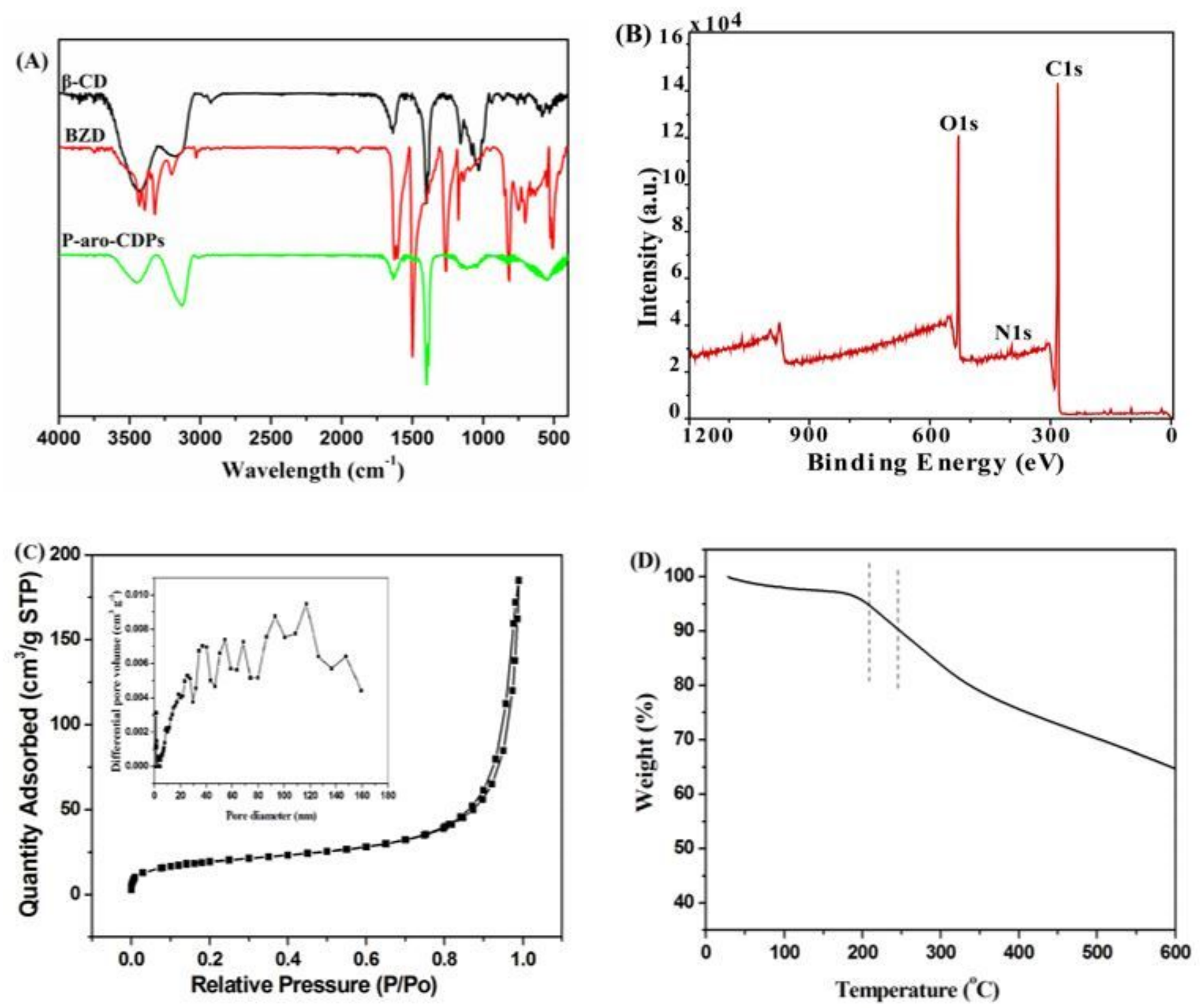

Figure 2

FTIR spectra (A), XPS spectrum (B), N2 adsorption-desorption isotherm (C), and TGA curve (D) of P-aroCDPs. 

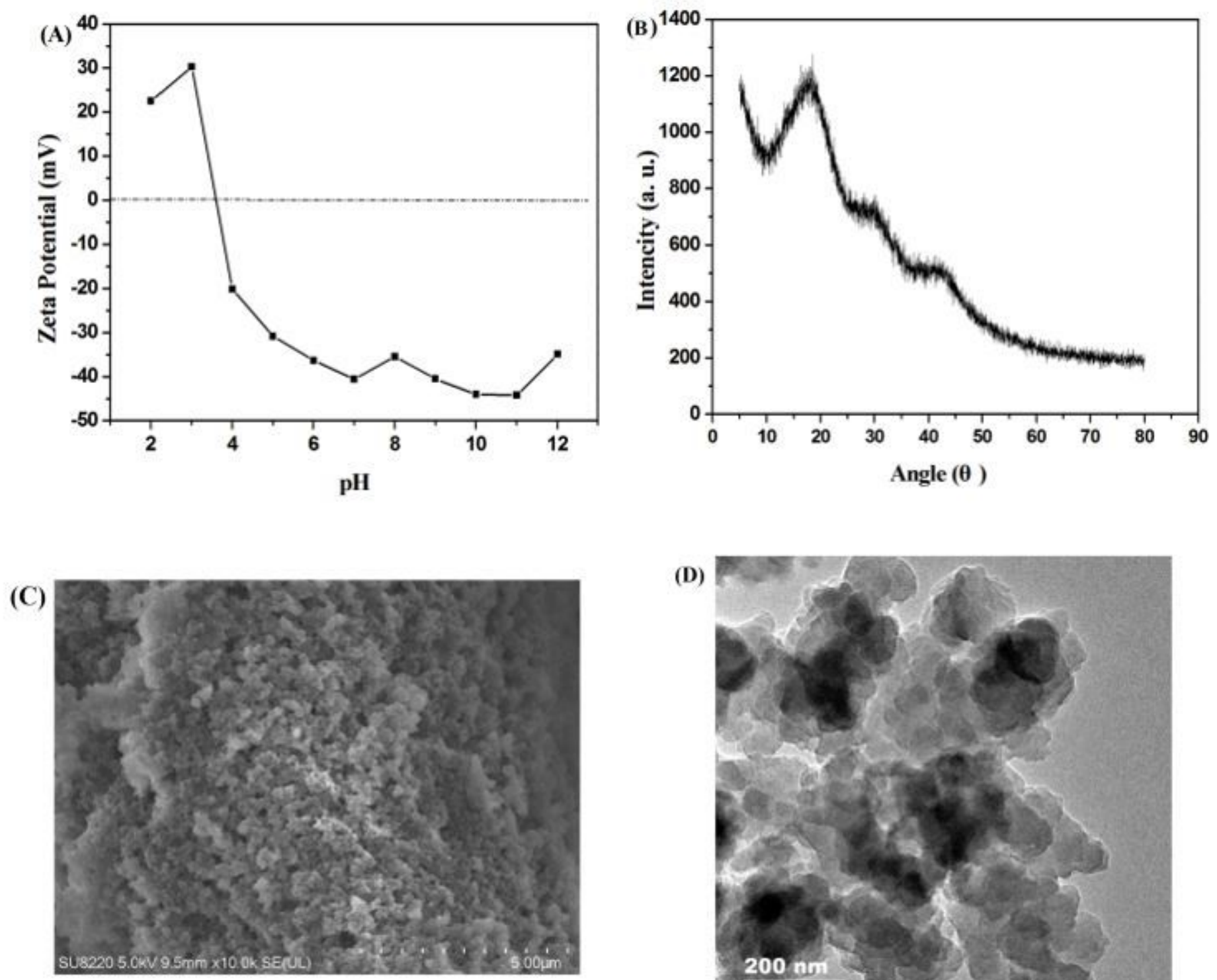

(D)

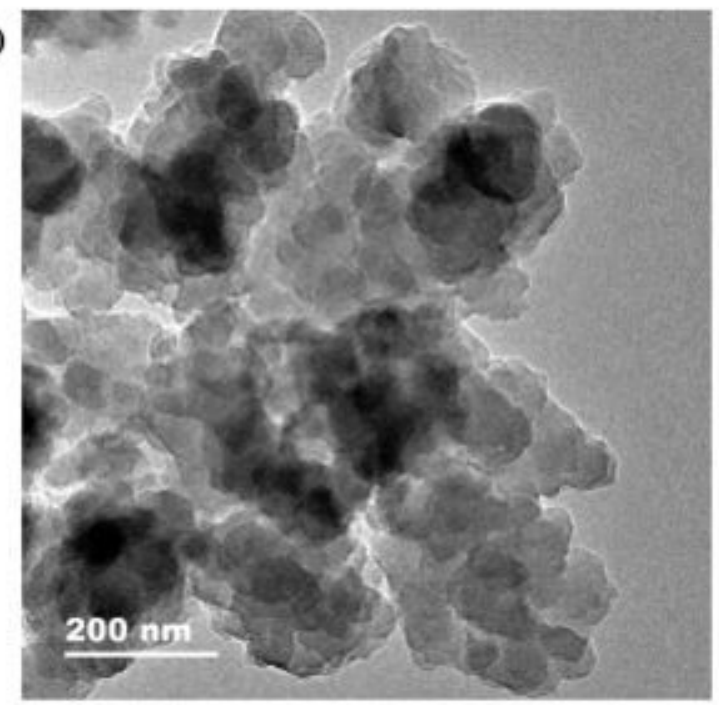

\section{Figure 3}

Zeta potential curve (A), XRD pattern (B), and SEM (C) and TEM (D) images of P-aro-CDPs. 

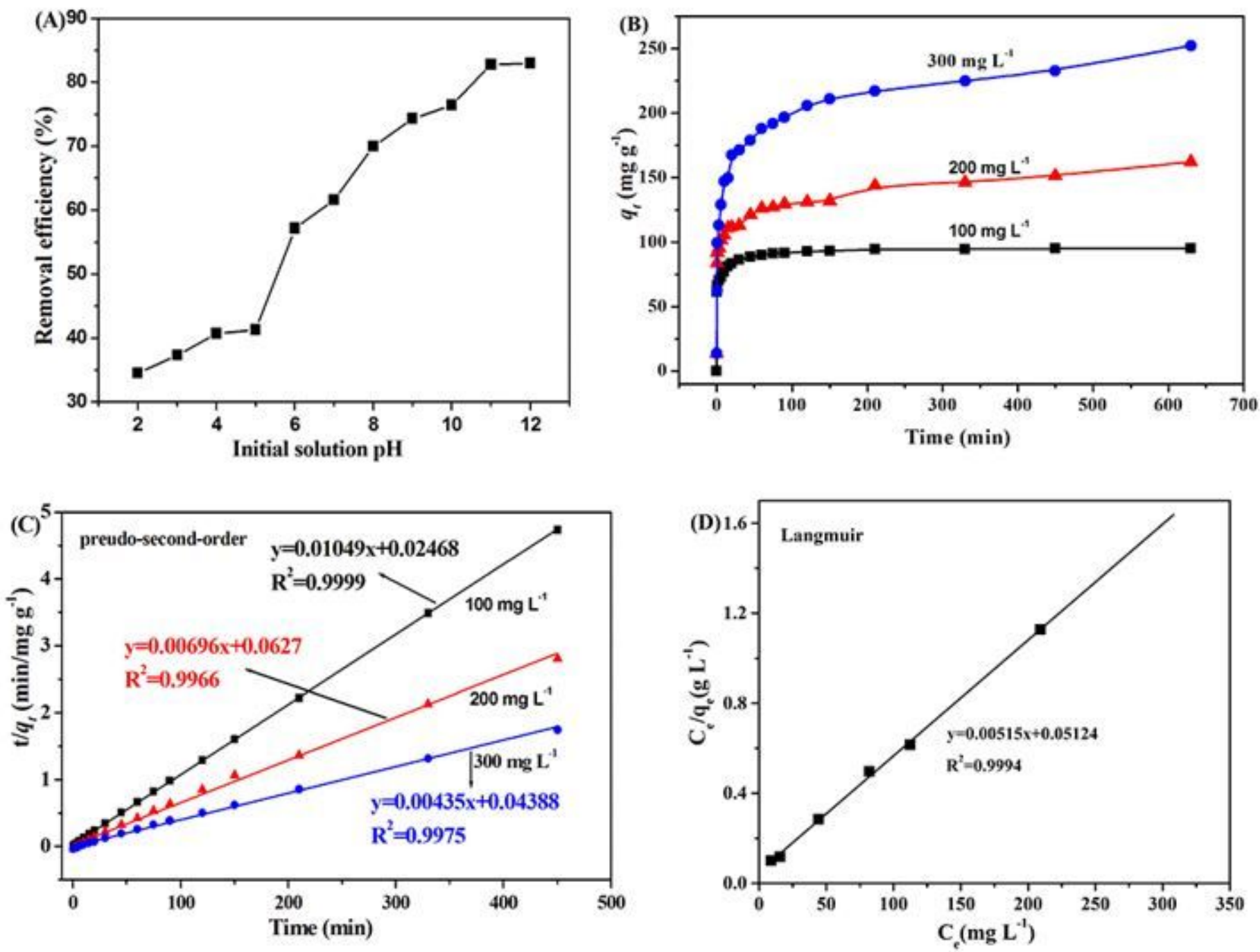

\section{Figure 4}

Influence of $\mathrm{pH}(\mathrm{A})$ and adsorption time (B) on the adsorption of MB on P-aro-CDPs. Data fitting to the pseudo-second-order equation (C) and the Langmuir adsorption isotherm (D). 

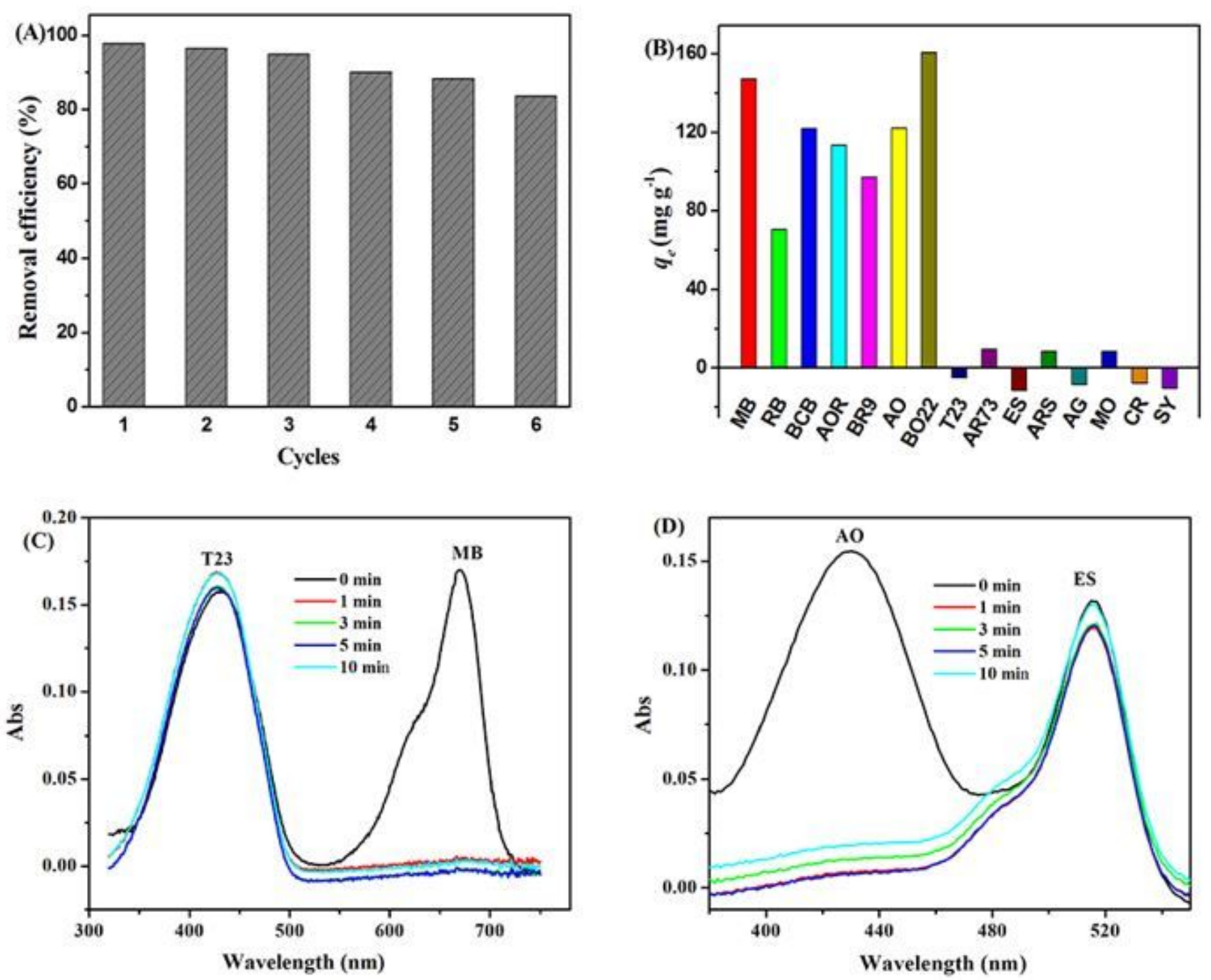

Figure 5

(A) Adsorption cycling tests. (B) Adsorption selectivity toward various dyes. (C, D) UV-vis spectra of mixed dye solutions before and after the adsorption on P-aro-CDPs.

\section{Supplementary Files}

This is a list of supplementary files associated with this preprint. Click to download.

- abstractgraphic.png

- SupportingInformation.docx 